Est Ag 37 (2002) 249-274

\title{
Los adversarios paulinos en 2 Corintios
}

No es una tarea sencilla mostrar el desarrollo de la comunidad cristiana de Corinto después de haber intervenido Pablo mediante su primera misiva en dicha comunidad. Podemos vislumbrar en su correspondencia posterior algunos rasgos de su evolución. Pero la segunda carta canónica a los corintios presenta una serie de problemas que no son fáciles de resolver: datación, relación con 1 Cor, unidad de la carta... El reconocimiento de que la 2 Cor no presenta una unidad literaria en el sentido de una carta conexa, continua y compuesta originalmente se puede considerar como una premisa común de la investigación neotestamentaria, aunque de vez en cuando se defienda una opinión distinta. Por tanto, un recopilador unió varias cartas de Pablo, originalmente independientes, en una única carta. La discusión sobre la unidad de la carta es importante para su interpretación. Sin embargo, una presentación detallada de toda esta problemática sobrepasa el objetivo de nuestro trabajo ${ }^{1}$, por lo que no analizaremos aquí esta cuestión. Secundo personalmente la posición y opinión que $R$. Bieringer defiende 2 .

Dentro de las relaciones entre Pablo y su comunidad, el conflicto con los oponentes de Pablo es un acontecimiento importante para el desarrollo de la comunidad de Corinto. En el siguiente estudio nos centraremos en la cuestión

${ }^{1}$ Un estudio detallado y profundo sobre las distintas hipótesis de una posible división de la carta nos la ofrece $R$. Bieringer, Teilungshypothesen zum 2. Korintherbrief. Ein Forschungsüberblick, in: ders. - J. Lambrecht, Studies on 2 Corinthians (BEThL 112), Leuven 1994, 67-105. Cfr. los cuadros sinópticos: Teilungshypothesen und Briefsituation; Teilungshypothesen und Einheitlichkeit in der Forschung, p. 96s. Véase también $G$. Dautzenberg, Der zweite Korintherbrief als Briefsammlung, in: ANRW II 25.4 (1987) 30453066.

$2 R$. Bieringer muestra en su artículo "Plädoyer für die Einheitlichkeit des 2. Korintherbriefes. Literarkritische und inhaltliche Argumente" in: ders. - J. Lambrecht, Studies 131-179, que sobre todo en los capítulos 1-9 no existe ningún problema serio de crítica literaria para justificar una hipótesis de división o recopilación de cartas anteriores. Hay, por el contrario, una serie de argumentos de crítica literaria en los capítulos 1-7 que avalan y confirman su unidad redaccional, así como para los capítulos 10-13. 
de la identidad de dichos enemigos en la segunda carta a los corintios. En primer lugar, tendremos que analizar si Pablo tuvo que hacer frente a unos mismos y únicos enemigos en las distintas partes de 2 Cor. Una serie de estrechas coincidencias y relaciones entre 2 Cor 2,14-7,4 y 2 Cor 10-13 indica que en ambas partes de la carta podría tratarse de la misma fase del conflicto. Comparto la opinión mayoritaria, según la cual Pablo hizo frente a un mismo grupo de oponentes en 2 Cor 2,14-7,4 y 2 Cor 10-13. Así resume V.P. Furnish este consenso general: "La oposición de la que Pablo es consciente cuando escribe la primera carta (cap. 1-9) es esencialmente la misma que él agudamente condena en la carta más tardía (cap. 10-13). Las personas en cuestión no son, como los adversarios de Pablo en 1 Cor, residentes en Corinto y miembros de la comunidad; son personas ajenas $(11,4)$ que por medio de cartas de recomendación $(3,1)$ han tratado de establecerse allí como autoridades apostólicas en el territorio evangelizado por Pablo (10,12-18)"3. Sin embargo, en los primeros capítulos de la carta las referencias a sus enemigos no son tan explícitas como en los capítulos 10-13. Por eso, no es de extrañar que la mayoría de los exégetas busquen en primer lugar la identidad de los adversarios en los cap. 10-13, y con los datos obtenidos intenten esclarecer las alusiones a los oponentes de los cap. 1-7.

Discutida es la relación entre los maleantes ( $\left.\dot{\alpha} \delta 1 \kappa \eta ́ \sigma \alpha_{\varsigma}, 7,12\right)$ o el incidente mencionado en 2 Cor 2,5-11 y la problemática de los enemigos en 2 Cor 2,14-7,4, o bien en los capítulos 10-13. Las semejanzas y diferencias entre el incidente y la cuestión de los enemigos no permiten concluir con seguridad si los dos conflictos estaban relacionados entre sít ${ }^{4}$ Pablo no aporta indicios concretos sobre la identidad de los $\dot{\alpha} \delta ı \kappa^{\prime} \sigma \alpha \varsigma$ ni de los enemigos. Tampoco explicita la causa ni el contenido del conflicto. Por tanto, existen dos posibilidades: a) Son dos conflictos distintos, b) se trata de dos aspectos claramente

${ }^{3}$ V.P. Furnish, II Corinthians (AnBib 32A), Garden City 1984, 52.

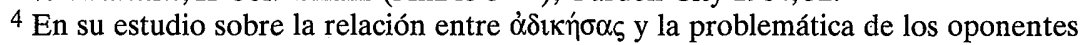
en la discusión exegética llega $R$. Bieringer, "Plädoyer" 142-160, a la siguiente conclusión: Entre los defensores de la hipótesis de que 2 Cor está compuesta de varias cartas independientes, se defiende tanto la identificación como la diferenciación de ambos conflictos. Independientemente de ello, todos ellos ven especialmente en las afirmaciones sobre la reconciliación en 7,5-16 una confirmación de la reconciliación total, incluida la cuestión de los enemigos. Por el contrario, los defensores de la unidad de la carta diferencian entre el conflicto $\alpha \dot{\delta} \delta$ iń $\sigma \alpha_{\varsigma}$ y la problemática de los enemigos y, según estos autores, el texto 7,5-15 no da ninguna indicación sobre la reconciliación con los enemigos. Cfr. C.K. Barrett, O $\mathrm{A} \triangle \mathrm{IKH} \Sigma \mathrm{A} \Sigma$ (2 Cor. 7,12), in: ibidem., Essays 108-117, quien recoge casi todas las interpretaciones que se han dado al respecto. 
diferenciados de un mismo conflicto 5 . Sin embargo, parece claro que 2 Cor 2,5-11 y 7,5-16 tratan, en resumidas cuentas, de una cuestión concreta y, como mucho, de un aspecto determinado del asunto de los enemigos. Por tanto, es comprensible que se hubiera alcanzado la reconciliación por lo que respecta al incidente y ésta, por otra parte, se contemplara todavía en el amplio marco del conflicto de los enemigos. Algunos indicios indicarían que en 2 Cor 2,147,4 y en los cap. 10-13 se trataba de un problema más importante y fundamental que el del incidente 6 .

Otra cuestión que ha despertado también el interés de los investigadores es la siguiente: ¿Tuvo Pablo que enfrentarse en 2 Cor con los mismos enemigos que en 1 Cor? La identidad e identificación de los enemigos en 2 Cor se consideró en la antigua historia de la investigación siempre en dependencia de la cuestión de la relación entre 1 y 2 Cor $^{7} .2$ Cor se interpretaba desde el trasfondo de 1 Cor y se presuponía de identidad de los enemigos en ambas cartas. Se utilizaba, por tanto, la información e indicaciones de 1 Cor para la identificación de los enemigos de 2 Cor. Pero como ya hemos indicado anteriormente, nos encontramos en 2 Cor ante una nueva problemática. La mayoría de los exégetas modernos pone en duda la unidad de los adversarios y ve conflictos con distintos rivales en cada una de las cartas a los corintios. La situación en 2 Cor había cambiado respecto a la situación de 1 Cor, dado que durante el periodo de la composición de las dos cartas canónicas se habrían

\footnotetext{
${ }^{5}$ Aunque del texto de 2 Cor nos parece muy difícil poder afirmar con seguridad si la

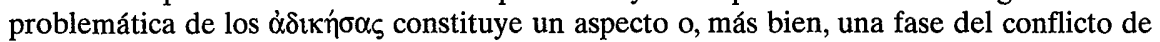
los rivales o una crisis independiente del conflicto, retenemos en contra de los defensores de la hipótesis de Schmithals-Bornkamm que la insistencia a la reconciliación en 6,11-13 y 7,2-4 no son un ruego o requerimiento para superar el conflicto de los maleantes descrito en 2,5-11 y 7,5-16. Del mismo modo, tampoco es el conflicto de los maleantes el problema fundamental con el que se enfrenta Pablo en los capítulos 10-13. R. Bieringer llega a la con-

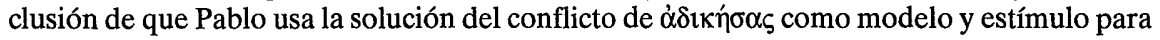
que los corintios pusieran fin de la misma manera al conflicto de los rivales o enemigos.

${ }^{6}$ R. Bieringer, "Plädoyer" 160.

${ }^{7}$ La uniformidad o unidad del frente enemigo en las cartas dirigidas a Corinto fue postulada en primer lugar por F.C. Baur. Este autor intenta mostrar que Pablo tuvo que hacer frente a un único grupo de judaístas en las dos cartas. Siguiendo a este estudioso, aunque con algunas variantes, otros han postulado la identidad de un único frente enemigo como judaístas C.K. Barrett, J.J. Gunther, G. Lüdemann etc. Otra corriente de investigación ve en los gnósticos a los únicos oponentes de Pablo tanto en 1 Cor como también en 2 Cor. (p.e. W. Lütgert, W. Schmithals, R. Bultmann). D. Georgi y sus seguidores consideran a los enemigos como judeocristianos helenistas (apóstoles carismáticos itinerantes de origen helenístico-judío), los cuales se presentaban en la comunidad al modo de los predicadores

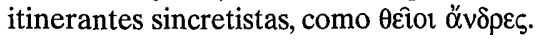


infiltrado predicadores foráneos en Corinto, cuyo objetivo era cuestionar la legitimidad del apostolado paulino con el fin de socavar la autoridad de Pablo en la comunidad. Las luchas de partidos (1 Cor 1-4) habían pasado a un segundo plano y ya no jugaban ningún papel relevante 8 . Pablo no habría aplicado a sí mismo el slogan del partido de 1 Cor, lo que él, sin embargo, hace

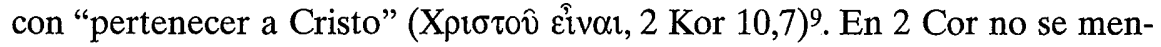
cionan más los nombres de Apolo, Pedro, Bernabé (1 Cor 9,5) ni Santiago (1 Cor 15,7). Algunos estudiosos postulan la llegada de nuevos adversarios, quienes pusieron en marcha un movimiento en contra de Pablo. Estos nuevos adversarios habrían ganado para su causa a algunos de los antiguos oponentes paulinos, que anteriormente habrían participado en las rivalidades de partidos $^{10}$. Los nuevos adversarios se convirtieron, sin embargo, en los cabecillas y en los líderes de los oponentes. Por consiguiente, debemos distinguir y diferenciar los enemigos de las dos cartas.

Es difícil determinar cuándo Pablo habla de los enemigos infiltrados en Corinto y cuándo se refiere a los miembros de la comunidad corintia. Por eso opinan muchos exégetas que ciertos corintios habrían aceptado las tesis de los intrusos, y que los oponentes y varios miembros de la comunidad de Corinto constituyeron a los ojos de Pablo un único frente ${ }^{11}$. La responsabilidad principal de esta oposición caía, sin embargo, en los "superapóstoles".

La mayoría de los exégetas concuerdan en lo siguiente: a) Está casi fuera de toda duda que los llamamientos a la reconciliación en 2 Cor 6,11-13 y en 7,2-4 se refieren a las tensas y amenazantes relaciones entre Pablo y los corintios, originadas éstas por el conflicto con los adversarios. b) La reconciliación descrita en 2 Cor 2,5-11 y 7,5-16 permite todavía una apelación a la reconciliación en la misma carta como la que tenemos en 2 Cor 6,11-13 y en 7,2-4, dado que cada uno de los llamamientos mencionados se refieren a distintos aspectos del mismo problema o incluso a distintos problemas. Además, 2 Cor 2,5-11 y 7,5-11 no describen evidentemente un restablecimiento total de las buenas relaciones en todos los aspectos. c) Una comparación de la dureza y

${ }^{8}$ H.-J. Klauck, 2 Kor 11, presupone que las luchas de los partidos de 1 Cor se acababan de solucionar.

9 Ibidem, 79.

10 P. Marshall, Emnity 260-265, considera a los "hybrists" de 1 Cor y a los "apóstoles rivales" de 2 Cor como dos grupos distintos, pero estarían aliados entre ellos de alguna manera.

${ }^{11}$ Por el contrario, otros autores piensan que el frente hostil no sería tan homogéneo como aparece en 2 Cor. 
gravedad del conflicto permiten presuponer que 2 Cor 2,14-7,4 y cap. 10-13 tratan del mismo conflicto aunque de distintas fases.

Discutido es, sin embargo, una precisa identificación de los adversarios. Para Pablo no era tan importante abordar la identidad religiosa de los adversarios, sino la interpretación errónea del cristianismo que proponían. Por eso, el apóstol no da ninguna información concreta sobre ellos. Y lo que conocemos de los oponentes no proviene de un escrito de Pablo dirigido a los rivales, sino sólo lo que Pablo dice a la comunidad corintia sobre ellos. Los corintios no necesitan que se los describan y Pablo tampoco da una imagen objetiva. ¿Quiénes eran éstos?

\section{Resumen de la investigación histórica sobre la oposición en 2 Cor 12}

La problemática de la rivalidad en 2 Cor ha sido analizada en la historia de la interpretación de diversas maneras. Casi nada nuevo se puede decir al respecto, por eso los ensayos y artículos modernos que se ocupan de esta cuestión defienden con pequeñas variantes alguno de los modelos fundamentales ya existentes en la investigación. Aquí presentamos un sumario de las hipótesis más importantes que se han dedicado a investigar el tema de la oposición y rivalidad en 2 Cor y han intentado identificar a los enemigos. Con ello queremos descubrir si la misión de Pablo en Corinto chocó con un determinado movimiento rival cristiano y por qué motivos.

\section{A) Los enemigos como judaístas}

Ya hace dos siglos defendió F.Chr. Baur la tesis de que la misión paulina en Corinto (es decir, la teología paganocristiana universalista de Pablo) entró en conflicto con los judaístas (es decir, con el judeocristianismo particularista y exigente-legalista introducido por Pedro). Estos judeocristianos, fieles a la ley y de origen palestino, habrían recibido el encargo de parte de la primitiva comunidad de Jerusalén de extender su influencia a la comunidad corintia.

12 Algunos artículos y comentarios han presentado en los últimos tiempos buenas y detalladas descripciones de la historia de la investigación referente a los oponentes en 2 Cor. Para el status quaestionis cfr. N. Hyldahl, "Parties" 19-32; P.F. Beatrice, "Avversari" 125; R.P. Martin, "Opponents". 279-289; C. Ginami, Gli pseudo-apostoli in 2 Cor, in: R. Penna (Hrsg.), Antipaolinismo: Reazioni a Paolo tra il I e il II secolo (RSR 2), Bologna 1989, 55 64; J.L. Sumney, Identifying 147-177; R. Penna, "Presence" 7-41; R. Bieringer, "Gegner" 193-221. 
Esta hipótesis identifica más o menos los enemigos de 2 Cor con los judaístas de Galacia, y presupone en ambas cartas el mismo frente enemigo, para lo cual se apoya en el pasaje 2 Cor 11,22-2513. A pesar de las duras críticas que se hicieron a esta hipótesis, la explicación de Baur fue prácticamente aceptada universalmente hasta principios del siglo $\mathrm{XX}$, y aún hoy se defiende con pequeñas variantes ${ }^{14}$. C.K. Barrett interpreta кovóv y $\mu \dot{\varepsilon} \tau \rho o v$ en 2 Cor 10,1218 en relación a los acuerdos misioneros alcanzados en el sínodo de Jerusalén y entiende el concepto de $\psi \varepsilon v \delta \alpha \pi o ́ \sigma \tau 0 \lambda 01$ como dirigido contra los judaístas. Los $\psi \varepsilon v \delta \alpha \pi \delta ́ \sigma \tau 0 \lambda \circ$ serían, por consiguiente, delegados que representaban indignamente a sus dirigentes ${ }^{15}$.

La equiparación e identificación de los enemigos en 2 Cor con los oponentes de Galacia plantea a los estudiosos problemas en cuanto al mensaje teológico. En primer lugar, no se encuentran en 2 Cor las principales exigencias judaístas, tan discutidas en Gal, como son el deber de la circuncisión y la observancia de la ley. La ausencia de las típicas demandas judaístas (observancia del sabbat, normativa alimentaria y circuncisión) ${ }^{16}$ se explicaría según esta hipótesis como una simple táctica misionera para hacer el cristianismo más atrayente. En segundo lugar, difícilmente se pueden explicar los elementos pneumáticos que encontramos en Corinto dentro de los grupos judaístas.

13 En el prólogo de Marción a las cartas de Pablo leemos: "Los de Acaya oyeron la palabra de la verdad del apóstol y fue pervertida de distintas maneras por falsos apóstoles, algunos por la elocuencia verbal de la filosofía, otros por la secta de la ley judía", tomado de R.P. Martin, "Opponents" 279.

14 B. Witherington III, Conflict 346, n. 49: "Me gustaría afirmar que los oponentes eran judeocristianos, pero 'judaizantes' es un término demasiado fuerte, sobre todo teniendo en cuenta que su programa no contenía la exigencia de la circuncisión, ni el sábado ni las leyes sobre los alimentos; nada de eso se menciona en 2 Cor. Sugiero que eran judeocristianos pneumáticos con interés por la sophia". Algo parecido ya había apuntado J. MurphyO'Connor, Paul. A Critical Life, Oxford 1996,303, según el cual la mezcla de indicios señalan a dos grupos distintos: judeocristianos y pneumáticos.

15 C.K. Barrett, "Opponents" 251, resume su tesis con las siguientes palabras: "Los intrusos eran judíos, judíos de Jerusalén, judíos judaizantes... Los corintios, enfrentados por estos apóstoles rivales, se pusieron a comparar y a juzgar entre ellos en base a motivos esencialmente helenistas. Es probable que la situación se complicó más por la disponibilidad de los apóstoles intrusos para aceptar los criterios propuestos por los corintios, y, por tanto, para adoptar una medida de helenización - uno podría casi decir, de 'corintianización'... Él [Pablo] no reconoció los presupuestos corintios como criterio de apostolicidad".

16 Ibidem, 252: "La insistencia en la circuncisión no es un rasgo indispensable de los judaizantes. Existían misioneros judíos que no insistían en la circuncisión [Josephus, AJ XX 40-48] y tenemos en Gal 2 la evidencia más clara de un movimiento judaizante suficientemente fuerte para excomulgar a iglesias gentiles, las cuales habían renunciado sin embargo a la afirmación de que la circuncisión era necesaria para la salvación". Cfr. F.W. Horn, Der Verzicht auf die Beschneidung im frühen Christentum, in: NTS 42 (1996) 492s. 
La solución a ese problema estaría según C.K. Barrett y G. Lüdemann en que los adversarios judaístas provenientes del exterior habrían creado una alianza con los enemigos pneumáticos paganos existentes anteriormente en Corinto. Los intrusos rivales, judaístas, aceptaron los criterios helenistas sobre la concepción de un verdadero apóstol, tal como lo entendían los corintios. Esta adaptabilidad de los judaístas la explica C.K. Barrett mediante las tres distintas corrientes teológicas (conservadora, liberal y revolucionaria) dentro judeocristianismo de la iglesia primitiva. Los misioneros llegados a Corinto pertenecerían al judeocristianismo liberal y aceptaron por motivos misioneros elementos sincretistas gnósticos y pneumáticos de la religión pagana. Los falsos apóstoles procedían del círculo de Pedro, quien no insistía en la circuncisión de los paganocristianos. Así se aclararía la ausencia de este tema en 2 Cor. Una posición semejante defiende G. Lüdemann ${ }^{17}$.

P.W. Barnett intenta mejorar la tesis de C.K. Barrett. Afirma que la misión de los judaístas en Corinto fue doble: "It was first, to reinforce Jewish converts in a conservative and ongoing Judaism. Secondly, it was to judaize Gentile Christians to the extent of having them observe the fourfold decree of James"18. Los enemigos apelaron al decreto de Santiago (Hech 15,23-29), Pablo, por el contrario, a los acuerdos alcanzados en Jerusalén y transmitidos en Gal 2,7-9. Otros autores ven en las distintas orientaciones del judaísmo el origen de los elementos sincretistas que los judaístas cristianos habrían heredado ${ }^{19}$.

Los defensores de la hipótesis judaísta presuponen, en general, el origen palestino de los enemigos. Su teología, a pesar de las tendencias sincretistas, estaba marcada fuertemente por influencias del judaísmo, por lo que el conflicto de Corinto habría que entenderlo desde un trasfondo judío. En la historia de la investigación la hipótesis judaísta no fue aceptada unánimemente, por lo que se propusieron otras hipótesis para su discusión.

17 G. Lüdemann, Paulus Bd. 2,141-143, ve la causa de la hostilidad y rivalidad paulina en estrecha relación con la conferencia de Jerusalén. Mientras que la oposición paulina en Galacia insistía y se empeñaba en la judaización de los paganocristianos, surgieron en Corinto defensores de una posición media más liberal, los cuales eran partidarios y seguidores de Pedro.

18 P.W. Barnett, "Opposition" 10 s.

19 J.J. Gunther, "Opponents" 315ss. Este autor identifica el frente rival antipaulino con personas de distintas ramas de los esenios. Contra la crítica dirigida a Barrett, de que los éxtasis (2 Cor 5,13), las visiones $(12,1.7)$ y los hechos portentosos $(12,12)$ eran desconocidos para los judaístas, afirma P.W. Barnett, que ésos ya constituían en aquella época dentro del medio ambiente religioso de Judea componentes usuales de la apocalíptica judía (Josephus, BJ II 258f.). E.E. Ellis, "Paul" 289, explica los elementos pneumáticos en los rivales en base a "las manifestaciones pentecostales de la iglesia de Jerusalén". 


\section{B) Los oponentes como gnósticos}

Se acepta normalmente que 2 Cor contiene junto a elementos judaístas también elementos helenistas-pneumáticos o gnósticos. Los defensores de la hipótesis judaísta, sin embargo, confieren a estos elementos gnósticos una importancia secundaria en el conflicto corintio. Por contra, los defensores de la hipótesis gnóstica colocan los elementos pneumatológicos en el centro del conflicto. Además, subrayan y acentúan la ausencia de las exigencias típicamente judaizantes (Sabbat, circuncisión, leyes alimentarias), así como la ausencia de la problemática de la justificación por la fe. Por otra parte, intentan explicar los elementos judaístas existentes desde otras perspectivas.

El punto fundamental del conflicto se encuentra para esta hipótesis en el pasaje central de la carta: 2 Cor 11,4. El texto trata las distintas concepciones del pneuma. Los enemigos eran pneumáticos, entusiastas, judeocristianos liberales, que provenían y tenían su origen en un movimiento protognóstico de origen judío. La libertad paulina la habrían corrompido en libertinaje y la fe la habrían sustituido por la gnosis. De distintas maneras se ha intentado buscar el origen de este grupo. Según $A$ Schlatter, los enemigos eran un grupo de judaístas que había sido expulsado de la comunidad cristiana primitiva por motivo de sus tendencias gnósticas y libertinas ${ }^{20}$. H. Windisch defiende la hipótesis de un doble frente contra Pablo: una oposición pneumática-gnóstica surgida en la misma ciudad de Corinto y otro frente compuesto por predicadores judíos itinerantes. Ambos grupos se habrían unido en contra de Pablo. Los dirigentes del grupo eran los oponentes provenientes del exterior, pero como compromiso con el otro grupo no pudieron imponer sus exigencias judaístas y tuvieron que aceptar algunas posiciones gnósticas ${ }^{21}$. $W$. Schmithals intenta mostrar el origen de este grupo gnóstico corintio dentro del judaísmo. La teología herética en Corinto era una gnosis independiente. En la correspondencia corintia nos encontramos por primera vez una confrontación entre una misión helenista y otra gnóstica en el ámbito del cristianismo. Aquí se habría desarrollado un sistema de "Christusgnosis" precristiano, una gnosis con su mito del salvador salvado. Los gnósticos son misioneros de origen judío y, probablemente, ya estaban diseminados en la diáspora.

Esta hipótesis gnóstica encontró sobre todo en la exégesis alemana sus $\operatorname{adeptos}^{22}$. Siempre se ha criticado que la presunción de una gnosis formada y

\footnotetext{
20 A. Schlatter, Die korinthische Theologie (BFChTh 18,2), Gütersloh 1914, 110-114.

$21 \mathrm{H}$. Windisch, Der zweite Korintherbrief (KEK VI), 9. Aufl., Göttingen 1924, $25 \mathrm{~s}$.

22 Para los defensores de esta hipótesis cfr. Bieringer, "Gegner" 203, n. 86.
} 
estructurada en Corinto a mediados del siglo I d.C., constituye un anacronismo. Según R.McL. Wilson se debe diferenciar claramente el material realmente gnóstico del siglo 2 d.C. del pregnóstico. El material pregnóstico no se puede considerar en sentido estricto como gnóstico. Esta teoría que considera a los rivales paulinos como gnósticos no superó el riesgo de interpretar los documentos neotestamentarios a la luz de las ideas procedentes del siglo II d.C.23. Dado que la hipótesis gnóstica no puedo convencer a los exégetas, pronto se propuso otra solución.

\section{C) Los enemigos como judeocristianos helenistas ${ }^{24}$}

Esta teoría busca a los rivales de Pablo en la sinagoga helenista y en la apologética misionera de la diáspora. La opinión propuesta por $F$. Büchsel, según la cual detrás de los enemigos tenemos un judaísmo influenciado por

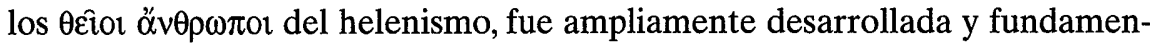
ta por $D$. Georgi ${ }^{25}$. Su investigación dio como resultado la siguiente tesis: 2 Cor estaba dirigida contra la actividad de misioneros itinerantes judeocristianos, quienes según 1 Cor se habían infiltrado en la comunidad corintia. Estos misioneros itinerantes se presentaban como taumaturgos y como $\theta \varepsilon \hat{i o r}$

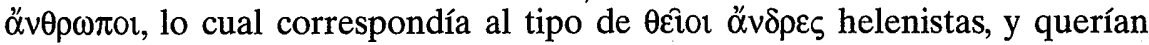
demostrar el poder de su dios mediante hechos extraordinarios, espectaculares y, al mismo tiempo, legitimarse a sí mismos. Su autorización la obtenían de su pneumatismo. Íntimamente unido a lo anterior estaba la manifestación personal ostentosa, el don de la palabra (elocuencia), la realización de poderosos milagros y la experiencia de visiones y éxtasis.

Este modelo de misioneros existía ya en el judaísmo helenista. Moisés y José

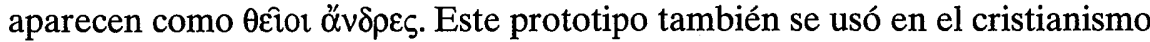

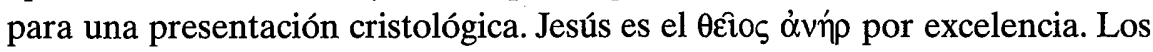

23 R.McL. Wilson, Gnosis and the New Testament, Philadelphia - Oxford 1968; ibidem, Nag-Hammadi and the New Testament, in: NTS 28 (1982) 289-302.

24 Cfr. F. Lang, Die Briefe an die Korinther (NTD 7), Göttingen 1994, 359: “Los adversarios son predicadores itinerantes judeocristianos-helenistas, los cuales se vanaglorian de una posesión especial del espíritu y pertenencia a Cristo... Probablemente habían venido a Corinto desde el territorio sirio de la misión petrina, tal vez como 'enviados' de Antioquía". Cfr. también ibidem, Paulus und seine Gegner in Korinth und in Galatien, in: $H$. Lichtenberger (ed.), Geschichte - Tradition - Reflexion. Bd. 3: Frühes Christentum. FS. Martin Hengel, Tübingen 1996, 427.

25 G. Georgi, Gegner 
enemigos paulinos en 2 Cor serían defensores de esa cristología y de una concepción misional pneumática basada en dicha cristología.

Esta teoría encontró mucha aceptación entre los exégetas ${ }^{26}$ hasta principios de los años ochenta. Sin embargo, en los últimos decenios ha sido muy criticada. Muchos estudiosos rechazan la identificación de los enemigos con la

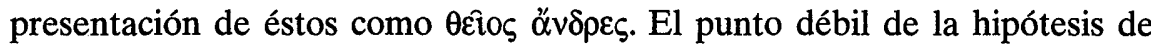

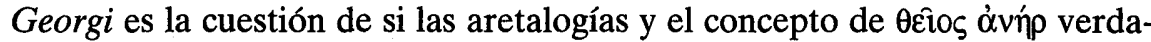
deramente encontraron entrada y acogida en el judeocristianismo primitivo. El problema está en que la noción de $\theta \varepsilon \hat{\varepsilon} 0 \varsigma$ àvíp no aparece expresamente en 2 Cor. Esta categoría cultural es una construcción moderna. Los elementos que contienen nuestra carta son demasiado vagos, indirectos y marcados por la polémica paulina, como para permitirnos una conclusión de este género. Por eso se ha intentado buscar la identidad de los enemigos en otras direcciones del judeocristianismo helenista.

\section{D) Nuevas perspectivas}

Siguiendo los pasos de $A$. Schlatter, E. Käsemann ${ }^{27}$ postula otra hipótesis, según la cual en 2 Cor 10-13 encontramos un proceso clarificador intracristiano respecto a la relación entre Pablo y los primeros apóstoles ${ }^{28}$. El conflicto giraría entorno a una delimitación de fronteras entre un cristianismo

\footnotetext{
26 Partidarios de esta teoría se encuentran en R. Bieringer, "Gegner" 207, n. 102. Por el contrario, p.e. P.F. Beatrice, "Avversari" 22-25, considera a los misioneros como "predicatori encratiti, portatori di un'interpretazione teologica globale del messaggio cristiano, nutrita nello stesso tempo di spiritualità giudeo-ellenistica e di entusiasmo cristiano primitivo, e generata, in ultima istanza, dall'esperienza pre-pasquale della sequèla del Gesù storico" (p. 24). Esta "enkrateia" estaba constituida por una síntesis de los siguientes elementos: "antropologia greca dualista di matrice orfina e pitagorica, l'ascetismo giudeo-ellenistico di affinità filoniana, la tradizione battista palestinese ed il kèrigma cristiano" (p. 24). Según N. Hyldahl, "Parties" 19-32, los oponentes eran defensores o partidarios de la "sabiduría y filosofía judeohelenista, del mismo tipo que se encontraba en Alejandría, representada en primer lugar y sobre todo por Filón" (p. 28). A. B. Kolenkow, Paul and Opponents in 2 Cor 10-13 - Theioi Andres and Spiritual Guides, in: L. Bormann - K. Del Tredici - A. Standhartinger (Hrsg.), Religious Propaganda \& Missionary Competition in the New Testament World (NT.S 74), Leiden 1994, 351-374, indica que el conflicto entre Pablo y sus

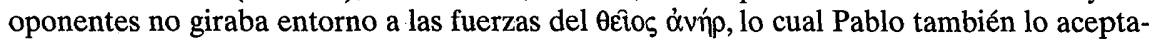
ba. "He argues in terms of method and role" (p. 371). Los conflictos estaban unidos a los métodos de liderazgo espiritual y cómo los intermediarios o los dirigentes y los seguidores se relacionaban entre sí (p. 373).

27 E. Käsemann, "Legitimität" 33-71.

28 En la investigación se cataloga la posición de $E$. Käsemann normalmente entre las hipótesis judaístas. J.L. Sumney, Identifying 63 , critica esta atribución y ve la diferencia fun-
} 
puro y un cristianismo impuro, entorno a diferencias doctrinales intraeclesiales: no se trata de una refutación de herejías, sino de la autodefensa de Pablo contra el entusiasmo cristiano y el tradicionalismo. La rivalidad consistía concretamente en la discusión sobre la legitimación de Pablo como apóstol por parte de los primeros apóstoles, los cuales se consideraban a sí mismos como la única instancia de control dentro del cristianismo. Aquí, por tanto, se enfrentarían dos concepciones distintas de entender la autoridad y, en parte, el conflicto se remontaría a conflictos personales.

En su comentario a la segunda carta a los Corintios, H.-J. Klauck considera a los enemigos como misioneros del cristianismo primitivo con estrechos contactos con la comunidad de Jerusalén. El conflicto en Corinto sería una continuación de las discrepancias entre Pablo y los primeros apóstoles sobre la misión a los paganos. En 2 Cor 10,12-16 habla Pablo de una norma o criterio ( $\mu$ ź $\uparrow o v)$, del acuerdo de Jerusalén ( $\mathrm{Gal} 2,9)$. Con esto indica o entiende Pablo el encargo que le confirió la conferencia de Jerusalén y, al mismo tiempo, reprocha a sus enemigos que no cumplan o se atengan al concordato alcanzado en Jerusalén. Éstos tenían otra concepción judía distinta de la misión a los paganos y una interpretación diversa del acuerdo de Jerusalén ${ }^{29}$. Esta misma opinión viene defendida en el comentario de R.P. Martin ${ }^{30}$. Los oponentes en Corintio serían enviados de los dirigentes judeocristianos, quienes ponían en tela de juicio la legitimidad de Pablo como apóstol. Una nueva variante de esta posición nos la ofrece $F$. Zeilinger: Los enemigos, procedentes de Antioquía, propondrían una nueva evangelización, dado que dudarían de la legitimidad de la misión paulina ${ }^{31}$.

J.L. Summey se adhiere a la posición de E. Käsemann, aunque cuestiona y niega la estrecha relación de los oponentes con los apóstoles de Jerusalén. De los resultados de su investigación, concluye que los rivales no eran nece-

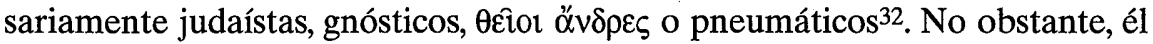

damental y decisoria en que el tema conflictivo entre Pablo y sus oponentes se centra en el espíritu. También $R$. Bieringer, "Gegner" 209, n. 107, considera la posición de Käsemann como independiente y separada de toda identificación histórico-religiosa de los enemigos.

${ }^{29}$ H.-J. Klauck, 2 Kor 11.

30 R.P. Martin, 2 Cor liii-lxii; 336-341. Esta opinión la cambió en un artículo posterior,

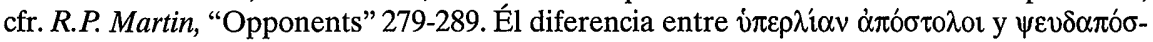

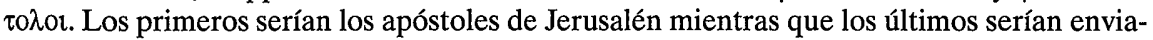
dos de una facción helenista antioquena.

31 F. Zeilinger, Krieg und Friede in Korinth. Kommentar zum 2. Korintherbrief des Apostels Paulus. Part I: Der Kampfbrief, der Versöhnungsbrief, der Bettelbrief, Wien Köln-Weimar 1992, 28.

32 Ibidem, 147: "Los datos no apuntan específicamente a judaizantes, gnósticos, hombres divinos o pneumáticos... Es posible que los oponentes eran pneumáticos en el sentido de que deseaban manifestaciones estáticas del espíritu, pero esto tampoco es seguro". 
se inclina por considerarlos pneumáticos, ya que subrayan y resaltan la revelación del espíritu en los apóstoles (p. 179). Todo el debate entre sus oponentes y Pablo gira entorno a la cuestión: ¿cómo se manifiesta el poder divino, es decir, el Espíritu en la vida de un apóstol legítimo? (p. 147). Según la opinión de los enemigos, esto se reconoce por medio del éxito, de la elocuencia, de la realización de milagros, de la aparición poderosa y en el ejercicio de la autoridad, mientras que para Pablo el poder de Dios se muestra más bien en la debilidad y en el sufrimiento.

Una posición distinta defiende G. Theißen ${ }^{33}$. Según este autor, en Corinto surgió un conflicto entre distintos tipos de misioneros, el carismático itinerante procedente de la campesina Palestina y el organizado, típico de la comunidad urbano helenista. En el centro del conflicto estaría según $G$. Theißen la cuestión del derecho de manutención, el cual se transforma en una disputa teológica centrada en la legitimación apostólica. Los enemigos no eran herejes, sino simplemente misioneros cristianos normales, cuya teología era similar a Mt 10. G. Theißen coloca el conflicto en el ámbito de rivalidades personales y en la necesidad de una interpretación actualizada, la cual era exigida por una nueva situación.

Esta perspectiva sociológica ha abierto nuevas puertas para la investigación. Por ejemplo, $P$. Marshall no identifica a los enemigos con enviados oficiales de la primitiva comunidad de Jerusalén ${ }^{34}$. Él denomina a los oponentes üßpıs (orgullosos, soberbios...), ricos e influyentes hombres de Corinto que ofrecieron regalos a Pablo. El desprecio de tales regalos por parte de Pablo fue interpretado como un gesto hostil y como rechazo de la amistad. Cuando Pablo aceptó los regalos de los filipenses (Flp 4,18), los corintios se sintieron ofendidos. Esto llevó a la desconfianza, al recelo e insultos y, finalmente, al intento de sustituir a Pablo por otros apóstoles que habían sido invitados a Corinto. Los nuevos apóstoles, también hybristen, eran judíos helenistas, dotados de elocuencia, pertenecían al movimiento fundamental de la cultura greco-romana y reclamaban o exigían el status apostólico. Se mostraban como ricos y poderosos, y humillaban a Pablo. Éste, por el contrario, rechazaba el sistema de valoes establecido por los rivales, según el cual al 'enviado' se le otorgaba un status social.

33 G. Theißen, "Legitimation" 221.

${ }^{34}$ P. Marshall, Enmity 259-265. Véase también V.P. Furnish, 2 Cor 54; E.A. Judge, Cultural Conformity and Innovation in Paul. Some Clues from Contemporary Documents, in: TynB 35 (1984) 15. 
G. Friedrich ${ }^{35}$ considera a los enemigos como gente del círculo de la iglesia jerosolimitana en torno a Esteban. Pero en 2 Cor no hay ningún indicio o dato que nos permita hacer esta suposición. Otros autores ven en los adversarios a judeocristianos helenistas, aunque consideran que no es posible una identificación más precisa ${ }^{36}$.

Hay quien los identifica con sofistas que aceptan ayudas por su trabajo $(2,17)$. Ben Witherington ${ }^{37}$ afirma que el principal problema en 2 Cor es la concepción corintia del líder cristiano. Algunos se habrían formado en sus mentes una imagen de apóstol modelada según los parámetros de su cultura, por lo que el líder tenía que poseer honor, poder, dones espirituales, habilidades retóricas, buenas referencias o recomendaciones y aceptar el patronato. Ellos buscaban un sofista o, al menos, un filósofo adepto a la retórica. Este autor aporta diez razones para justificar la existencia de estos filósofos y de esa forma de vida en Corinto durante esa época. En esta misma línea $B . W$. Winter opina que el pasaje 2 Cor 10-13 hay que entenderlo dentro del con-

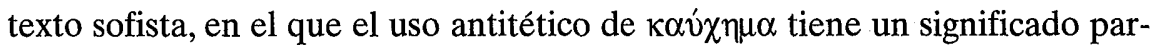
ticular. 2 Cor 11-12,10 constituye una parodia irónica de la vanagloria y una comparación irónica de sus oponentes, típica entre los sofistas. Con ello, Pablo busca en 11,12 socavar la reivindicación de ésos que buscaban el reconocimiento como misioneros o apóstoles con el correspondiente status. Pablo intenta demostrar que esos maestros eran, en realidad, locos y sus reivindicaciones sin sentido. Aquí no tendríamos miembros de la comunidad que eran sabios según los parámetros de su época, sino maestros entrenados en la retórica que rechazaban unirse (join in becoming fools) para llegar a ser sabios como cristianos" 38 .

Otros estudiosos buscan un trasfondo judío para los enemigos. Hay evidencias en 2 Cor $3^{39}$ y en 11,22, dos tipos distintos de contextos, para sugerir que eran judíos. Un intento de buscar una nueva solución en esta dirección ha sido postulada por J. Carrón Pérez. Analiza en primer lugar los datos aportados en los cap. 1-7, y llega a la sorprendente conclusión: "Pablo está litigando

35 G. Friedrich, "Gegner" 181-215.

36 Cfr. R. Bieringer, “Gegner" 208, n. 105.

37 Ben Witherington III, Conflict 348s.

38 B.W. Winter, Philo and Paul among the Sophists (MSSNTS 96), Cambridge 1997, 221-230, aquí 228.

$39 \mathrm{~J}$. Lambrecht, Structure and Line of Thought in 2 Corinthian 2,14-4,6, in: $R$. Bieringer - J. Lambrecht, Studies 279, insiste en que la polémica en 3,7-18 está dirigida contra los judíos, no contra los adversarios judeocristianos de Pablo. En 2 Cor 3 vuelve a la polémica, originalmente dirigida a la sinagoga, contra los adversarios que dentro de la iglesia atacan su misión gentil. 
o, si se prefiere tiene siempre presente a la hora de escribir a una gente que no puede ser más que judía"40. Por tanto, los adversarios paulinos ya no serían cristianos. Para ello estudia, siguiendo la exégesis propuesta por M.E. Thrall ${ }^{41}$ en su comentario a 2 Cor, algunos pasajes donde los enemigos serían gente judía: a) En 2 Cor 1,3s Pablo habla de una tribulación compartida por Cristo, Pablo y los corintios. Esta tribulación podía ser sólo una persecución $\mathrm{u}$ hostilidad de parte de los judíos. Pablo trataría del acoso que padecen los cristianos de Corinto, muchos de ellos judíos, por parte de los judíos que no han creído en el evangelio" (p. 172). Pablo intentaría con 2 Cor que los cristianos no sucumbieran ante el judaísmo ${ }^{42}$. b) Los textos 2,15 (los que se pierden) y 4,3-4 (los incrédulos) estarían dirigidos contra los judíos que han rechazado la predicación de Pablo y por ese motivo son incluidos entre los que se pierden. Son los judíos los que negocian con la palabra de Dios. "Si los $\pi 0 \lambda \lambda$ oí de 2,17 son los mismos que los $\tau$ ive $\zeta$ y ambos son judíos... como va a confirmar el capítulo 3 , los portadores de las cartas de recomendación son judíos y a ellos y a su pretensión de superioridad del ministerio de la antigua alianza va a responder Pablo a lo largo de todo el capítulo poniendo de manifiesto la superioridad del ministerio de la nueva alianza con respecto a la antigua" (p. 176). Estos judíos compararían a Pablo con la figura de Moisés, quien carecería del esplendor del mediador de la alianza del Sinaí. c) El apóstol también tendría en su punto de mira a los judíos no creyentes en 3,14, pues siguen leyendo el AT con un velo que les impide su auténtica comprensión.d) En el pasaje 5,11-

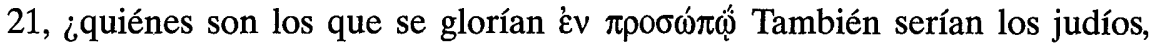
quienes se gloriaban del rostro glorificado de Moisés como testigo del esplendor de la antigua alianza. e) En el mismo contexto interpreta el pasaje 6,147,1 : los corintios deben evitar el trato con los $\alpha \pi i \sigma \tau o$, es decir, con sus adversarios judíos que no creen en Cristo. Nuestro autor concluye que si partimos

40 J. Carrón Pérez, Los adversarios de San Pablo en 2 Corintios, en: EstB 57 (1999) 163-187, aquí 171.

${ }^{41}$ M.E. Thrall, A critical and exegetical commentary on the Second Epistle to the Corinthians (International Critical Commentary of the Holy Scriptures of the Old and New Testament), Edimburg 1994, 113: "Lo que subyace en el trasfondo en los capítulos 3-6 es la crítica judía (no judeocristiana) de Pablo y su mensaje dirigida contra la comunidad de Corinto y que preocupa, al menos, a algunos de ellos. El mismo Pablo había sufrido esta oposición (Hech 18,5-17), de una forma más violenta y hostil, y puede haber considerado las dificultades actuales de los corintios con los críticos judíos, como al menos, análogas a su propia experiencia de persecución a manos de los judíos, y quizá como susceptible de convertirse en algo más similar y más amenazante".

42 Parece que este autor presupone la misma identidad judía de los oponentes en 2 Cor y en Gal (p. 172). 
del acuerdo general de que en 2 Cor 1-7 y 10-13 se trata de los mismos adversarios, entonces tenemos una contradicción patente: en los cap. 1-7 tendríamos adversarios judíos mientras que en los cap. 10-13 serían adversarios cristianos de origen judío. J. Carrón no dice claramente que los enemigos paulinos en 2 Cor 10-13 fueran judíos.

La problemática en Corinto hay que entenderla, según estas posiciones y opiniones, como una controversia cristiana (ad intra) y específicamente situacional. Algunas de la teorías expuestas en este apartado están muy cercanas a la hipótesis judaísta, pero hay una diferencia fundamental: las cuestiones teológicas y rituales de la controversia judaísta, como eran por ejemplo la circuncisión y el nomismo (la ley), no juegan ningún papel. El conflicto no se desencadenó por temas o contenidos histórico-religiosos. La multiplicidad de diferentes intentos para explicar la identidad de los enemigos se debe al hecho de que Pablo no transmite ninguna indicación precisa sobre su identificación, como se verá a continuación.

\section{La caracterización de los enemigos según Pablo}

Se puede aceptar que los adversarios pertenecen al movimiento cristiano $(10,7 ; 11,13 ; 11,22)$. Pablo se refiere a ellos sólo de forma indirecta y utiliza construcciones impersonales: $\pi 0 \lambda \lambda o^{\prime}\left(2,17 ; 11,18^{43}\right), \tau \iota \varsigma(10,7 ; 11,20.21) \tau \imath v \varepsilon \varsigma$ $(3,1 ; 10,2.12)$ o ó đo10v̂tos $(10,11)^{44}$. Los menciona sólo de paso, según lo cual el apóstol sigue las antiguas convenciones retóricas: mediante el anonimato no les concede el status de enemigos ${ }^{45}$. La presentación de los rivales mediante el uso de verbos está muy influenciado por el juicio negativo de Pablo. El elemento más objetivo que se obtiene de los verbos para un retrato robot, es

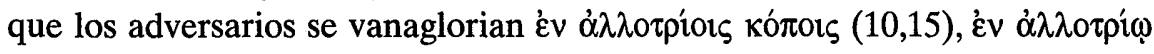

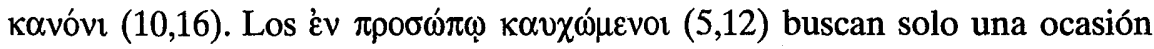

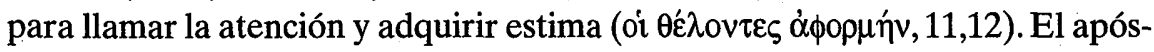

43 Se trata aquí seguramente de una exageración retórica. No es necesario pensar en un número elevado: "Il suffit de penser à une pluralitè de rivaux, quantifiables en un petit groupe de quelques personnes", R. Penna, "Presence"17.J.-H. Klauck, 2 Kor 11, piensa que serían tres o cuatro misioneros itinerantes.

44 R. Penna, "Presence" 14-25, analiza todas las formas gramaticales y lexicales, que son usadas en 2 Cor 10-12 para una descripción o caracterización de los oponentes paulinos.

45 V.P. Furnish, 2 Cor 49; P. Marshall, Emnity 325-339. Es digno de consideración la ausencia de adjetivos para la designación de los enemigos, lo que indica que el apóstol en su descripción no quiso abordar la naturaleza de los rivales. 
tol les critica que quieren esclavizar a los corintios ( $\kappa \alpha \tau \alpha \delta 0 v \lambda$ ó $\omega)$, robarles ( $\kappa \tau \varepsilon \sigma \theta^{\prime}(\omega)$ y tomarlos en su poder. Bofetean a los corintios y se engríen $(11,20)$. En otros pasajes de la carta también vienen presentados de forma

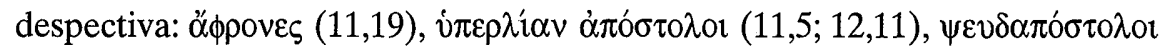

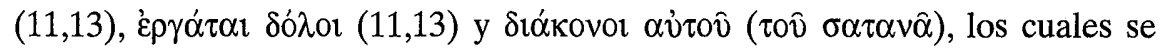
consideran ministros de justicia $(11,15)$; son ministros de Cristo, pero en menor grado que Pablo $(11,23)$.

Algunos autores ${ }^{46}$ ven en los últimos conceptos una alusión a dos categorías distintas de personas: Los $\psi \varepsilon v \delta \alpha \pi$ ó $\sigma \tau 0 \lambda$ or serían solamente enemigos concretos de Pablo en Corinto, los cuales son denominados como ministros de Satanás (cfr. los falsos hermanos en Gal 2,4). 2 Cor 11,5 y 12,11 ( $\tau \tilde{\omega} \nu$ v $\pi \varepsilon p \lambda i \alpha \nu$

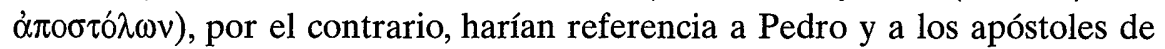
Jerusalén (cfr. Gal 2,6.9). La actitud paulina frente a los verdaderos apóstoles era, por tanto, muy respetuosa. Entonces los antagonistas de Pablo podrían

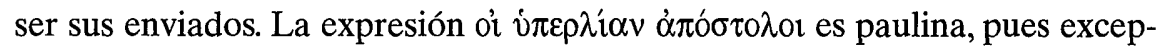
to en los dos pasajes de esta carta $(11,5 ; 12,11)$ no la encontramos en la literatura de la época. Se considera como una expresión paralela a $\psi \varepsilon v \delta \alpha \pi$ ó $\sigma \tau-$ $\lambda$ or (v. 13) pero con tono irónico y despectivo. Por lo cual no podemos identificar a los "superapóstoles" con los apóstoles de Jerusalén, pues Pablo los trata de forma más respetable ( $\mathrm{Gal} 2,6)$, y no osaría denominarlos siervos de Satanás ${ }^{47}$ (13-15). La crítica que hacen a Pablo en v. 6-7, la falta de elocuencia y el anuncio gratuito del evangelio, difícilmente se puede entender en boca de los apóstoles de Jerusalén. El contenido de la predicación de los intrusos es

46 Z.B. E. Käsemann, "Legitimität" 41-48; C.K. Barrett, "Opponents" 242-253; M.E. Thrall, "Super-Apostles" 42-57; R.P. Martin, "Opponents" 285ss.; J.M. Court, The Controversy with the Adversaries of Paul's Apostolate in the Context of his Relations to the Corinthians Congregation (2 Corinthians 12,14-13,13), in: E. Lohse, Verteidigung und Begründung des Apostolischen Amtes (2 Kor 10-13) (SMBenBE 11), Rom 1992, 96-99. Estos autores afirman que el tono con el que Pablo habla de los Superapóstoles es más reverente y respetuoso que cuando habla de los pseudoapóstoles. Pablo no se podría haber comparado con los falsos apóstoles, sobre todo porque él ya se había comparado en 1 Cor 15,9 con los principales apóstoles. Después de la doble repetición de la palabra "Superapóstoles" pasa Pablo a tratar el apoyo económico (en 11,7-11 y 12,13-18 respectivamente), y eso corresponde a la comparación en 1 Cor 9 con los otros apóstoles, el hermano del Señor y Cefas. Los $\psi \varepsilon v \delta \alpha \pi$ ó $\tau 0 \lambda$ ot son considerados como judaizantes radicales. Así entiende R.P. Martin, "Opponents" 285, ambos grupos de oponentes: "Los 'apóstoles exaltados' representan a los dirigentes de Jerusalén, mientras que los 'falsos apóstoles' pueden ser identificados con emisarios, bien enviados con o reclamando ser enviados con su apoyo... Los pseudoapóstoles estaban actuando ultra vires viniendo a Corinto".

47 Cfr. L.A. Johnson, Satan Talk in Corinth:The Rhetoric of Conflict, in: BibTheolBull 29 (1999) 145-155. 
más creíble en misioneros itinerantes helenistas que en enviados de la comunidad jerosolimitana.

Contra tal diferenciación entre pseudoapóstoles y superapóstoles hablan, sin embargo, otros argumentos ${ }^{48}$, de lo cual concluye V.P. Furnish: La evidencia sugiere fuertemente que Pablo tiene sólo un grupo en mente, es decir, esas personas que, desde su punto de vista, se han constituidos en Corinto como sus competidores.

¿Eran éstas autodenominaciones de los enemigos, que Pablo las había reformulado de forma negativa? Dado que esas designaciones constituían un ataque de Pablo contra la oposición, éste no ofrece un cuadro objetivo. No obstante, parte de la información que Pablo nos transmite, parece que sea objetiva. En 2 Cor 11,22-23a se compara Pablo con sus adversarios. Los tres

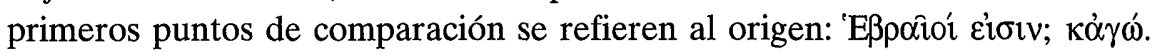

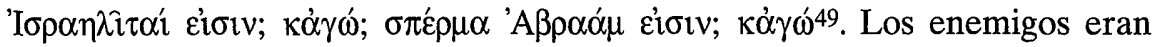
judíos en cuanto a la etnia y a la religión, y presumen de ello. Más discutido es si de ello se puede deducir o concluir su origen palestinense o, más bien, habría que considerarlos como judeocristianos helenistas de la diáspora. Las alusiones a sus cualidades y habilidades retóricas $(10,10 ; 11,6)$, a sus experiencias extáticas $(12,1-10)$ y a los hechos portentosos o prodigios $(12,12 ; 13,3)$ indican posiblemente una procedencia helenista-judaísta ${ }^{50}$. La autoconciencia, la arrogancia de ser descendientes de Abraham habla más a favor de que

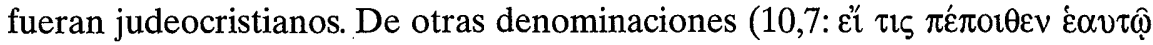

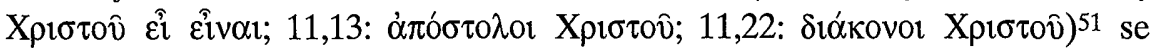
puede concluir que los enemigos pertenecen al cristianismo y que ellos vinieron a Corinto como misioneros y como apóstoles. Con los títulos de "apóstol", "siervo de Cristo" y "misionero" pretendían tener un relación especial con Cristo, igual o superior a Pablo. Anunciaron a los corintios un Jesús, un espí-

48 Algunos de estos argumentos se encuentran en V.P. Furnish, 2 Cor 494-505; S.E. McClelland, "Super-Apostles, Servants of Christ, Servants of Satan". A Response, in: JSNT 14 (1982) 82-87; R. Penna, "Presence" 24. Para la equiparación de los Superapóstoles con los pseudoapóstoles cfr. $N$. Hyldahl, The Corinthian "Parties" and the Corinthian Crisis, in: StTh 45 (1991) 28; P.W. Barnett, "Opposition" 3-5.

49 Una amplia discusión sobre estos términos se puede ver en D. Georgi, Gegner 5182. Según H.-J. Klauck, 2 Kor 88 , se podrían precisar más estos términos: se puede decir que, con 'hebreo' se indica la nacionalidad y la lengua. 'Israelita' es un nombre honorífico para el pueblo de Dios en la Escritura. 'Descendencia de Abraham' indica la certeza de ser portadores de la promesa.

50 V.P. Furnish, 2 Cor 53.

51 Cfr. D. Georgi, Gegner 31-38. 
ritu y un evangelio ${ }^{52}$ distinto al que Pablo les había predicado anteriormente $(11,4)$. Estas "afirmaciones explícitas" 53 sobre los rivales son aceptadas por la mayoría de los exégetas como información segura y fiable.

Las referencias explícitas a los adversarios: Una primera clara alusión a los adversarios la encontramos en 2,17. Pablo critica que la mayoría de los adversarios negocian con la palabra de Dios, es decir, que aceptan dinero por su enseñanza, por su ministerio pastoral (cfr. 4,2). Esta frase en sí, no nos permite deducir con seguridad si los oponentes hacían depender la legitimación apostólica de la aceptación del dinero, pero el contexto (v. 16c) sugiere esta conexión. A su vez, los misioneros rivales se proclaman a sí mismos y se hacen "señores" al gloriarse de sus "signos" especiales (4,5). El participio sustanti-

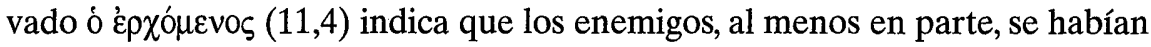
infiltrado en la comunidad. La forma singular de dicho participio se interpreta en sentido de una generalización o como colectivo ${ }^{54}$. Ellos son misioneros itinerantes e intrusos ${ }^{55}$ que han traspasado los límites debidos $(10,14)$ y que consiguen el acceso a la comunidad por medio de cartas de recomendación $(3,1)$. Estas cartas son usadas como evidencia de su status apostólico o de su autoridad, y exigirían de Pablo una prueba similar sobre su rango apostólico. No sabemos quién expediría dichas cartas de recomendación, pero probablemente provendrían de comunidades donde anteriormente habrían trabaja$\mathrm{do}^{56}$. Pablo no necesita recomendaciones de ningún tipo. "Solamente queremos daros ocasión para gloriaros de nosotros y así tengáis cómo responder a los que se glorían de lo exterior, y no de lo que está en el corazón" $(5,12)$. Los

52 El apóstol pone en tela de juicio que la predicación de los enemigos fuera cristiana. Según H.-J. Klauck, 2 Kor 83, Pablo hecha en falta seguramente en su predicación sobre Jesús la confesión o creencia en el crucificado $(4,5)$.

53 Véase J.L. Sumney, Identifying 95-113.

54 Otra posible interpretación propone R. Penna, "Presence" 18, para el singular: "Tout au plus peut-on penser ici à un leader des adversaires ayant valeur de représentant, mais qu'il ne faut pas identifier avec l'offenseur de 2,5-11; 7,12".

55 Esto también lo confirma la comparación de los enemigos con la serpiente $(11,3)$ y su caracterización como $\dot{\alpha} \pi$ ó $\sigma \tau 0 \lambda$ or $(11,5.13 ; 12,11)$. Es difícil precisar si todo el grupo de enemigos vino de fuera o si se juntaron con un grupo antagonista ya existente al interno de la comunidad.

56 Algunos autores habían propuesto que serían cartas de la iglesia de Jerusalén, dado que sólo ésta tenía la autoridad necesaria como para expedir dichas cartas (Cfr. E. Käsemann, "Legitimität" 45-47). Pero no hay en nuestro texto ninguna indicación que permita tal conclusión. Tampoco se tiene que presuponer que provengan de alguna autoridad, dado que los mismos corintios las pueden expedir $(3,1)$. 
adversarios se glorían de las apariencias, y les gusta comparar su ministerio y sus títulos ministeriales, cosa que Pablo no valoraba y consideraba como vanagloria.

El cambio de planes de viaje $(1,15.23)$ de Pablo fue malinterpretado en Corinto: Pablo tenía previsto ir a Corinto y pospuso su viaje. Es probable que este cambio haya sido interpretado por los adversarios como falta de integridad y fiabilidad del apóstol $(1,17)$ : lo que escribe no se corresponde con su actuación $(1,13)$. Además, su vida arrastrada y turbulenta (tribulaciones, persecuciones: 4,7-9) no habla a favor de la legitimación del ministerio paulino a los ojos de los adversarios. Todavía más, su vida y apariencia débil (6,3-9) desacredita su apostolado. Entienden la existencia apostólica de forma diferente a Pablo. Ellos creen que la vida del apóstol debe estar marcada por la fuerza y la habilidad para evadir la calamidad y estar por encima de la debilidad humana. Este sufrimiento y el tipo de vida del apóstol son muestra de una falta de espiritualidad. Por tanto, su comportamiento impropio incluye tanto su falta de integridad como su forma de vida.

Le critican que el mensaje paulino no es claro y sobre todo no tenía esplendor, es decir, que la señoría de Cristo venía ofuscada por la debilidad del apóstol: "Si nuestro evangelio está velado, lo está para los que se pierden, para los incrédulos, cuyo entendimiento cegó el dios de este mundo para impedir que vean brillar el resplandor del evangelio de la gloria de Cristo" (4,3-4). Pablo es consciente de que los incrédulos rechazan su evangelio. ¿Quiénes eran estos incrédulos? Algunos exégetas los identifican con los judíos, mientras que otros estudiosos consideran que serían los no-creyentes o perdidos de 2,15, es decir, cristianos que han rechazado o rechacen el mensaje paulino ${ }^{57}$. La repulsa del evangelio apostólico se relaciona con la actividad de Satanás (el dios de este mundo) (cfr. 11,13-15).

Pablo hace un reproche claro a los oponentes que se comportan como señores de los corintios, todo lo contrario que hace él: "Nosotros no intentamos dominar por la fuerza vuestra fe, sino colaborar a vuestra alegría, al manteneros firmes en la fe". Su autoridad apostólica impide a Pablo considerarse señor de la comunidad, pues es siervo de Jesús y está al servicio de la comunidad. Al contrario, la actitud de los adversarios (pseudoapóstoles) es típica de los déspotas: "Soportáis que os esclavicen, que os devoren, que os roben, que se engrían, que os abofeteen" $(11,20)$. 85 .

57 Chr. Wolff, Der Zweite Brief des Paulus an die Korinther (ThHK 8), Berlin 1989, 
Algunos autores creen ver en 5,16 que los adversarios habrían conocido a Jesús personalmente. Sin embargo, otros lo interpretan en referencia a la existencia antes de ser cristianos ${ }^{58}$.

Los capítulos 10-13 contienen muchos ataques de los rivales a Pablo ${ }^{59}$. 10,10-11 nos indica que los oponentes consideraron la debilidad de Pablo como prueba de que no tenía autoridad apostólica. 10,12-18 vuelve a tratar la crítica de las recomendaciones y Pablo responde a la acusación de ambición. Unos versículos más adelante encontramos otra vez la cuestión de la vanagloria: "Ya que tantos otros se glorían según la carne, también yo me voy a gloriar" $(11,18)$. De distintas maneras se ha entendido la expresión "según la carne". Las afirmaciones explícitas en los cap. 10-13 tienen como tema principal la forma apropiada de vida para los apóstoles. Según los adversarios, el verdadero apóstol debe ser una persona impresionante. Tiene que ser dinámico, locuaz en el hablar y tener una conducta dominante. Por eso actuaban como superiores hacia la comunidad de Corinto. Al mismo tiempo creían que los apóstoles deben presentar sus "títulos" a la comunidad para ser juzgados. Esto lo considera Pablo como vanagloria. Ellos usaban estos títulos para fundamentar su autoridad y sus derechos, entre los que se incluían la aceptación de honorarios. Los oponentes entendieron la aceptación de dinero (11,7-12; $12,13 ; 12,15 b-18)$ como signo y evidencia de un apostolado legítimo. Le podrían echar en cara que no era un verdadero apóstol, o lo interpretarían como que no amaba a los corintios. Puede que entendieran el estipendio de los apóstoles en términos de la relación cliente-patrón. Lo acusaban de fraudulento, afirmando que mientras rechazaba la ayuda económica de los corintios, se apropiaría de dinero destinado a la colecta de Jerusalén, por lo que así evitaba y se libraba de las obligaciones hacia la comunidad.

Tres temas interrelacionados dominan el debate entre Pablo y los adversarios en 2 Cor 10-13: a) la forma apropiada de vida para los apóstoles; b) la correcta manifestación para el espíritu en los apóstoles y c) los honorarios correspondientes a los apóstoles. Los tres temas se refieren a la legitimación del apostolado. El desacuerdo entre Pablo y sus rivales estaba centrado en la forma en que el Espíritu actuaba en la vida de los apóstoles, el cual tenía que operar de forma específica y especial. No parece que los intrusos hayan predicado una enseñanza distinta sobre la relación del Espíritu con Cristo o con

58 Cfr. S. Vidal, Las cartas originales de Pablo (Colección Estructuras y Procesos. Serie Religión), Valladolid 1996, 242, n. 53.

59 Véase p.e. 10,$2 ; 10,7 ; 11,5-6 ; 11,12-15 ; 11,20-21 \mathrm{a} ; 11,21 \mathrm{~b}-23 \mathrm{a} ; 12,11 \mathrm{c} ; 13,2 \mathrm{~b}-3$. 
el Padre, y tampoco parece que este espíritu tuviera alguna relación con el espíritu-Pneuma (o el Cristo cósmico) de la mitología gnóstica tardía.

En la carta hay varias alusiones indicando que el Espíritu es importante en la teología de los rivales. Éstos pensaban que el Espíritu se muestra de forma especial en los apóstoles. Es la fuente de sus vida poderosas. Creían que las experiencias visionarias demuestran el poder espiritual o su relación especial con el espíritu y eran una evidencia de la legitimidad del apostolado. Por otra parte, las afirmaciones referentes a la debilidad de Pablo $(10,8 ; 11,30$; $12,5-6 ; 12,10)$, indican que los oponentes perciben el uso de su autoridad como debilidad $(10,8)$. Pablo rechaza sus criterios para evaluar a los apóstoles y se gloría en la debilidad experimentada durante su vida $(11,30)$.

Las evidencias de 2 Cor 10-13 muestran que los rivales de Pablo enfatizaban la manifestación del espíritu en los apóstoles. El Espíritu es la fuente de sus vidas poderosas. Una presencia dominante e imponente es parte importante de lạ forma de vida de un apóstol. Esta presencia incluye una fuerte personalidad, el don de la locuacidad otorgada por el espíritu. El Espíritu también les permite realizar los "signos de un apóstol" y tener visiones. Ellos usan estos dones como evidencia para legitimidad de su apostolado. Rechazan la debilidad paulina, viendo en ella una constatación de que él no posee el espíritu, o al menos, no en la medida que ellos lo poseen. Por tanto, no es un verdadero apóstol.

Pablo reprocha a los corintios constantemente en 2 Cor 10-13, que ellos hayan aceptado acríticamente los criterios de los intrusos para la legitimidad de un apóstol y que hayan caído en sus garras opresoras sin haber opuesto resistencia. Por eso el apóstol pide a los corintios en su exhortación 13,3-10, que se examinen si todavía caminan en la fe. En este texto se encuentra un motivo importante para la disputa con Pablo: "Pues, ciertamente, Cristo fue crucificado en razón de su flaqueza, pero está vivo por la fuerza de Dios. Así también nosotros: somos débiles en él, pero viviremos con él por la fuerza de Dios en vosotros". La disputa giraría en torno a la debilidad y a la fuerza de Dios, al sufrimiento en el seguimiento del crucificado o a las habilidades pneumáticas, especialmente un discusión en la cuestión ¿cómo la fuerza del Cristo exaltado se hace patente y actúa en la predicación y en la vida de sus apóstoles? Resumiendo, podríamos decir que la discusión se centra en la contraposición de la theologia crucis de san Pablo y la theologia gloriae de los predicadores intrusos.

Conocemos poco sobre el mensaje teológico de los rivales, excepto lo que pensaban que debía ser la vida del apóstol. Su comprensión de la vida de los apóstoles puede que nos diga algo acerca de cómo entendieron la existencia cristiana en general. La confrontación entre Pablo y sus oponentes 
giraba en los capítulos 1-9 sobre la manifestación propia del poder divino en las vidas de los apóstoles. G. Friedrich ${ }^{60}$ resume otros dichos de Pablo, presuntamente polémicos, contra sus adversarios: a) Los adversarios poseían el don de la palabra espiritual $(10,10 ; 11,6)$, y apelaban a este don como signo del verdadero apóstol. b) Tanto los enemigos como Pablo consideran los

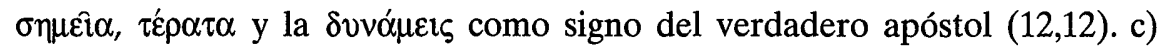
Pablo pone de relieve las visiones y los éxtasis $(5,12 \mathrm{~s} ; 12,1-5)$ porque los enemigos daban mucha importancia a esos fenómenos. d) Criticaban a Pablo que le faltaba el espíritu (Pneuma) y por eso no podía presentarse abiertamente (10,1-3). e) Aceptaban el derecho de sustento del misionero (11,7-10; 12,1316). f) De la mención de Moisés-Cristo ( 2 Cor 3 ) concluyen algunos exégetas que los rivales defenderían una visión cristiana primitiva que presentaba a Moisés como prototipo del Mesías. g) A los enemigos se les atribuye una falsa cristología: la muerte de Jesús no tendría ningún significado salvífico (cfr. 4,10-14; 5,16-21).

Las acusaciones e incriminaciones que Pablo achaca a los enemigos se refieren a su autocomprensión apostólica y a la relación de éstos como misioneros frente a los corintios. $R$. Bieringer resume estas acusaciones en tres apartados: Se trata en primer lugar de la legitimación de los apóstoles enemigos $(3,1 ; 5,12 ; 10.12 \mathrm{ab} ; 11,13.15 .18 .21-23 ; 12,11)$; en segundo lugar, del contenido predicado por los oponentes $(11,4)$ y, en tercer lugar, de la relación misionero-apostólica de los enemigos hacia los corintios $(2,17 ; 5,12 ; 11,13-15$; cfr. también 11,2-4 y 11,19-20). Pablo criticó a los enemigos que no se preocupaban de Dios ni de Cristo, sino sólo de sí mismos. Además, les reprochaba que hacían negocio con la Palabra de Dios $(2,17)$, hacían mal uso de las cartas de recomendación $(3,1)$. Se glorían sólo de lo exterior y no de lo que está en el corazón $(5,12)$. En su insensatez se comparan ellos así mismos $(10,12 b)$. Pablo y sus colaboradores, por el contrario, no se quieren "vanagloriar des-

60 G. Friedrich, “Gegner” 181-191. Cfr. también R. Bieringer, “Gegner” 190-193. M. Carrez, Réalité christologique et référence apostolique de l'Apôtre Paul en présence d'une église divisée (2 Cor 10-13), in: A. Vanhoye (Hrsg.), L'Apôtre Paul. Personalité, style et conception du ministère (BEThL 73), Leuven 1986,163-183, especialmente 164-174, enumera una serie de nueve características y rasgos de los oponentes: "Il sont judaïsants; ils possèdent la connaisance, la gnosis; friands d'expériences spirituelles hors du commun (ils sont experts en phénomènes d'inspiration); ils attribuent une grande importance à l'inspiration; ils aiment les signes, les miracles et les prodiges; le comportement des opposants fait craindre à Paul non seulement le refus de son apostolat, mais plus encore un rejet du Christ, un divorce $(11,2.3)$; ils semblent attacher un intérêt tout particulier au lien financier entre la communauté et leur apostolat; ils sont traités comme 'faux apôtres'; ils prèchent un autre Jésus, un autre esprit, un autre évangile". 
medidamente; antes bien, "nos mediremos a nosotros mismos por la norma que Dios mismo nos ha asignado como medida al hacernos llegar hasta vosotros" $(10,13)^{61}$.

De todos estos reproches es casi imposible obtener una identificación histórico-religiosa de los rivales. Pablo intentó con su crítica descalificar a sus oponentes y apartar de ellos a los corintios. Es de suponer que el apóstol no identificaba a la comunidad cristiana en Corinto, a pesar de sus relaciones tirantes con él, con sus enemigos. Él no rechaza de lleno sus doctrinas ante los corintios, sino que pone de relieve hasta qué punto los enemigos ignoran la esencia y el centro del mensaje cristiano. Pablo intentó presentar a los corintios cómo sus rivales habían fallado en la esencia de la fe cristiana. Los Corintios tienen que aprender a comprender y aceptar el verdadero evangelio de Jesucristo. "Si ellos eran judaístas, gnósticos, sincretistas-helenistas o defendían una doctrina de esos tipos, es irrelevante"62.

\section{Conclusión}

No es posible sustraerse a la impresión de que las teorías o hipótesis expuestas anteriormente son criticables y discutibles, porque las fuentes no permiten una identificación precisa. Las indicaciones que aparecen en las cartas no nos permiten clasificar a los enemigos dentro de los grupos mencionados. Ninguna de las identificaciones clásicas sobre los adversarios como juda-

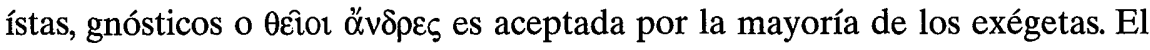
problema radica simplemente en que Pablo no estaba interesado en nombrar a sus enemigos ni describir detalladamente el contenido de su predicación. El apóstol quería mostrar a los corintios que los enemigos no anunciaban el verdadero evangelio.

61 El texto 10,12s. plantea a los exégetas algunas dificultades. Para una amplia y detallada discusión de este problema de crítica textual, véase V.P. Furnish, 2 Cor 470s. Muchos exégetas ven en el concepto "Kanon" ( $\alpha \nu \omega ́ v)$ un componente geográfico-local, en el sentido de zona de trabajo, esfera de influjo, territorio repartido, lo que se podría referir a Gal 2,9. Se trataría por tanto del acuerdo alcanzado entre Pablo y las autoridades cristianas de Jerusalén, y el apóstol protestaría contra su incumplimiento por parte de los enemigos, cfr. C.K. Barret, "Opponents" 65; G. Lüdemann, Paulus, Bd.2,139s. C.U. Manus, The Opponents of Paul in 2 Corinthians 10-13. An Exegetical and Historical Study , Diss. Leuven 1981, $265-$

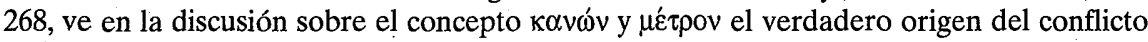
entre Pablos y sus adversarios. Cfr. H.-J. Klauck, 2 Kor 10-12. Según E. Käsemann, "Legitimität" 50s., el pasaje 2 Cor 10,12-18 se refiere a una disputa sobre el principio de legitimación de los Apóstoles de Jerusalén.

62 R. Bieringer, "Gegner" 189. 
De las afirmaciones paulinas obtenemos solamente un cuadro fragmentario de los rivales. Resumiendo podríamos decir de los enemigos: a) los adversarios paulinos son cristianos (2 Cor 10,7; 11,4; 13,23); no son ni judíos ni paganos a los que se pueda tildar con la etiqueta de "enemigos". En Corinto se trataba de un debate intraeclesial, lo cual testimonia un pluralismo en el tipo de misión. b) Ellos son carismáticos itinerantes, que se presentan como apóstoles ( 2 Cor 11,3.5; 12,13;11,23), se han infiltrado en una iglesia que ellos no han fundado ${ }^{63}$, y de ella aceptan ayudas económicas (2 Cor 11,7$12.20 ; 12,13-18)$. c) Está claro su origen étnico y religioso: judío. Y estaban orgullosos de ello.

Cuestiones historiográficas, sin embargo, permanecen abiertas. La primera se refiere a su origen judío: ¿Provienen los judeocristianos hostiles originariamente de Palestina o de la diáspora (helenistas)? ¿O se podría pensar en un grupo mixto? El segundo punto conflictivo gira entorno a su posición institucional: ¿Tenían ellos una relación directa con la primitiva comunidad de Jerusalén? ¿O eran autónomos? Su formación confesional-religiosa tampoco es clara: ¿Defendían una interpretación legalista del evangelio o eran más bien carismáticos? ¿O, por el contrario, no se interesaban del plano doctrinal y habría que considerar el conflicto únicamente dentro de un plano personal? Tenemos que remarcar y recalcar que los rivales corintios no se pueden identificar con los judaístas de Galacia o Filipo. Las principales exigencias judaístas (circuncisión y observancia de la ley) no se encuentran por ningún lado en 2 Cor. De la información paulina no se puede reconocer que la oposición quisiera reducir las tensiones de los cristianos con los judíos o con los romanos mediante una nueva evangelización, como había sido el caso en Galacia. Por consiguiente, el motivo para la constitución o formación de este frente enemigo no hay que buscarlo en el edicto de Claudio.

Un signo de la discusión intraeclesial se encuentra en el pasaje 10,13-16

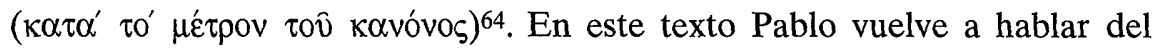

63 En un artículo, al cual no he tenido acceso, de C. Forbes, Paul's Opponents in Corinth, in: Buried History 19 (1983) 19-23 (vgl. NTAb 28 [1984] nr. 625) se subraya que tanto las acciones de los superapóstoles en Corinto como también las de los provocadores judíos de altercados en Alejandría, año 41, (cfr. la carta del emperador Claudio a los alejandrinos, PLond 1912) eran un signo del orgullo nacional judío.

64 J.F. Strage, 2 Cor 10:13-16: Illuminated by a Recently Published Inscription, in: BA 46 (1983) 167s, muestra lo que se esconde bajo esta expresión. Véase también E.A. Judge, The regional kanon for requisitioned transport, in: G.H.R. Horsley (Hrsg.), New Documents Illustrating Early Christianity. A Review of the Greek Inscriptions and Papyri, Bd. 1, North Ryde 1981, 36-44; Bd. 2, 88s. 
importante acuerdo del sínodo sobre la misión a los paganos, en el cual se llegó al compromiso de que Pablo y Bernabé se dirigirían a los paganos mientras que Pedro, Santiago y Juan a los circuncisos (Gal 2,7-10). La medida $(10,13)$ hace referencia al reparto de los campos de misión y, según Pablo, el mismo Dios lo había repartido. Pablo defiende su campo de acción y reprocha a los enemigos que ellos no hayan respetado los acuerdos alcanzados, ni el campo de acción estipulado para ellos. Además, el apóstol se considera que fue el primero que anunció el evangelio de Cristo en Corinto, lo cual le da prioridad para la evangelización de esa zona. Para Pablo, Corinto era un punto de apoyo importante y estratégico para su misión hacia el oeste $(10,16)$. Por eso le interesaba tanto conservar la lealtad de los corintios.

\section{Bibliografía}

BARNETT, P.W., Opposition in Corinth, in: JSNT 22 (1984) 3-17.

BARreTt, C.K., Paul's Opponents in II Corinthains, in: NTS 17 (1970-71) 233-254.

BEATRICE, P.F., Gli avversari di Paolo e il problema della Gnosi a Corinto, in: CrSt 6 (1985) $1-25$.

Carrón Pérez, J., Los adversarios de San Pablo en 2 Corintios, in: EstB 57 (1999) 167-187.

Ellis, E.E., Paul and his Opponents, in: Neusner, J. (Hrsg.), Christianity, Judaism and other Greco-Roman Cults. Studies for Morton Smith at Sixty, Leiden 1975, 282-292.

Friedrich, G., Die Gegner des Paulus im 2. Korintherbrief, in: Betz, O. - Hengel, M. SCHMIDT, P. (Hrsg.), Abraham unser Vater. Juden und Christen im Gespräch über die Bibel. FS O. Michel (AGJU 5), Leiden 1963, 181-191.

FuRNISH, V.P., II Corinthians (AncB 32A), New York u.a. 1984.

GEORGI, G., Die Gegner des Paulus im 2. Korintherbrief. Studien zur religiösen Propaganda in der Spätantike (WMANT 11), Neukirchen-Vluyn 1964.

GunTHER, J.J., St. Paul's Opponents and their Background. A Study of Apocalyptic and Jewish Sectarian Teaching (NT.S 35), Leiden 1973.

Hyldahl, N., The Corinthian "Parties" and the Corinthians Crisis, in: StTh 45 (1991) 19-32.

KÄSEMANN, E., Die Legitimität des Apostels. Eine Untersuchung zu II Korinther 10-13, in: ZNW 41 (1942) 33-71.

KLAUCK, H.-J., 2. Korintherbrief (NEB.NT 8), 3. Aufl., Würzburg 1994.

LüdemanN, G., Paulus, der Heidenapostel II: Antipaulinismus im frühen Christentum (FRLANT 130), Göttingen 1983.

Marshall, P., Enmity in Corinth: Social Conventions in Paul's Relations with the Corinthians (WUNT II 23), Tübingen 1987.

Martin, R.P., 2 Corinthians (WBC 40), Waco, Tex. 1986.

----The Opponents of Paul in 2 Corinthians: An Old Issue Revisited, in: HAWTHORNE, G.F. - BETZ, O. (Hrsg.), Tradition and Interpretation in the New Testament. FS E.E. Ellis, Grand Rapids, Mich. - Tübingen 1987, 279-289.

Sumney, J.L., Identifying Paul's Opponents. The Question of Method in 2 Corinthians (JSNT.S 40), Sheffield 1990.

THEISSEN, G., Legitimation und Lebensunterhalt: ein Betrag zur Soziologie urchristlicher Missionare, in: IBIDEM, Studien zur Soziologie des Urchistentums (WUNT 19), 2. Aufl., Tübingen 1983, 201-230). 
ThraLl, M.E., Super-Apostles, Servant of Christ, and Servants of Satan, in: JSNT 6 (1980) $42-57$.

Penna, R., La presence des adversaires de Paul en 2 Cor 10-13: Approche litteraire, in: LOHSE, E. (Hrsg.), Verteidigung und Begründung des apostolischen Amtes (2Kor 10-13) (SMBen.BE 11), Rom 1992, 7-41.

Witherington, B. III, Conflict and Community in Corinth. A Socio-Rhetorical Commentary on 1 and 2 Corinthians, Grand Rapids, Mich. - Carlisle 1994.

DAVID ÁlVAREz Cineira

Estudio Teológico Agustiniano

Valladolid 